\title{
Off-Label Medications in Pediatrics
}

\author{
Jeeson C. Unni ${ }^{1}$ (D) $\cdot$ Ranjit Baby Joseph ${ }^{1}$
}

Received: 8 January 2019 / Accepted: 3 July 2019 / Published online: 20 July 2019

(C) Dr. K C Chaudhuri Foundation 2019

To the Editor: Many medications used in pediatrics lack documentation regarding dosage, efficacy and safety because of the inherent problems of conducting trials in children. As a result, off-label use of drugs in this age group is common.

"Off-label" use refers to use of drugs not included in the package insert; not mentioned for a particular age, route of administration or duration; or not mentioned in the IAP Drug Formulary. Recent updates, not cited in standard textbooks, may also amount to 'off-label' use. However absence of labeling for specific age groups or specific disorder does not mean that the drug use is improper, as it may be due to lack of sufficient evidence [1]. A large number of medicines used in children are with reference to data extrapolated from adults.

Antibiotics are often prescribed "off-label" with regard to age, dosing and frequency of administration. Clinical trials that inform neonatal and pediatric antibiotic labeling are scanty. Overall incidence of using unlicensed antibiotics is around $11.4 \%$ and off-label prescribing is $46.6 \%$ [2]. This raises concern in the light of emerging multidrug-resistant pathogens.

Thirty-five percent of prescriptions for allergic disease were considered off-label; majority in children under 2 [3].

Off-label prescribing of antiepileptic drugs (AEDs) is common in pharmaco-resistant epilepsy. Conventional AEDs have limited efficacy in refractory neonatal seizures, resulting in use of newer agents, despite a lack of information about their safety or efficacy.

Jeeson C. Unni

jeeson1955@gmail.com

1 Department of Child Health and Adolescent Medicine, Aster Medcity, Kuttisahib Road, South Chittoor, Cheranalloor, Kochi, Kerala 682027, India
Studies show that at least $78 \%$ of pediatric cardiac cases receive one or more off label drugs; $31 \%$ receiving 3 or more [4].

In pediatric psychiatric patients, $32.3 \%$ prescriptions were off-label, $41.6 \%$ receiving at least one off-label prescription; most frequent category being low age [5].

Off-label medications are also common in pediatric gastroenterology and pediatric rheumatology.

Rational use of off-label medications may be permitted if it is of benefit to the child. Therapeutic decision-making should always be guided by the best available evidence. Larger clinical trials in children and establishment of regulatory bodies are need of hour for safe use of these medications in children.

\section{Compliance with Ethical Standards}

Conflict of Interest None.

\section{References}

1. Frattarelli DA, Galinkin JL, Green TP, et al; American Academy of Pediatrics Committee on Drugs. Off-label use of drugs in children. Pediatrics. 2014;133:563-7.

2. Laforgia N, Nuccio MM, Schettini F, et al. Off-label and unlicensed drug use among neonatal intensive care units in southern Italy. Pediatr Int. 2014;56:57-9.

3. Cabral AJ, Morais-Almeida M. Off label use of drugs in childhood asthma. Eur Respir Pul Dis. 2015;1:16-7.

4. Pasquali SK, Hall M, Slonim AD, et al. Off-label use of cardiovascular medications in children hospitalized with congenital and acquired heart disease. Circ Cardiovasc Qual Outcomes. 2008;1:74 83.

5. Braüner JV, Johansen LM, Roesbjerg T, Pagsberg AK. Off-label prescription of psychopharmacological drugs in child and adolescent psychiatry. J Clin Psychopharmacol. 2016;36:500-7.

Publisher's Note Springer Nature remains neutral with regard to jurisdictional claims in published maps and institutional affiliations. 